\title{
The evolution of treatment outcomes for resected stage IIIA non-small cell lung cancer over 16 years at a single institution
}

Linda W. Martin, MD, ${ }^{a}$ Arlene M. Correa, PhD, ${ }^{a}$ Wayne Hofstetter, MD, ${ }^{a}$ Waun Ki Hong, MD, ${ }^{\text {b }}$ Ritsuko Komaki, MD, ${ }^{c}$

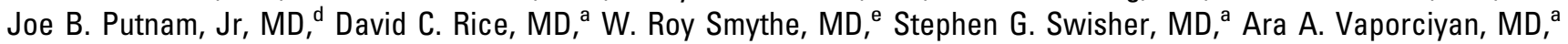
Garrett L. Walsh, MD, and Jack A. Roth, MD ${ }^{a}$

Supplemental material is available online.
From the Departments of Thoracic and Cardiovascular Surgery, ${ }^{a}$ Medical Oncology, ${ }^{\text {b }}$ and Radiation Oncology, ${ }^{\mathrm{c}}$ University of Texas MD Anderson Cancer Center, Houston, Tex; the Department of Thoracic Surgery, ${ }^{\mathrm{d}}$ Vanderbilt University Medical Center, Nashville, Tenn; and the Department of Surgery, ${ }^{\mathrm{e}}$ Texas A\&M University Health Science Center, College Station, Tex.

Read at the Eighty-fifth Annual Meeting of The American Association for Thoracic Surgery, San Francisco, Calif, April 10-13, 2005.

Received for publication April 8, 2005; revisions received July 28, 2005; accepted for publication Aug 8, 2005.

Address for reprints: Jack A. Roth, MD, FACS, The University of Texas MD Anderson Cancer Center, Professor and Chairman, Bud Johnson Clinical Distinguished Chair, Department of Thoracic \& Cardiovascular Surgery, Professor of Molecular \& Cellular Oncology, Director, W. M. Keck Center for Cancer Gene Therapy, Unit 445, Houston, TX 77230-1402 (E-mail: jroth@mdanderson.org).

J Thorac Cardiovasc Surg 2005;130:1601-10 $0022-5223 / \$ 30.00$

Copyright (C) 2005 by The American Association for Thoracic Surgery

doi:10.1016/j.jtcvs.2005.08.010
Objectives: The effect of multimodality treatment including surgical intervention, chemotherapy, and radiation for potentially resectable stage IIIA non-small cell lung cancer in a practice setting remains to be defined. To determine which treatment factors are associated with improved survival, we evaluated outcomes for these patients at our institution over a 16-year period.

Methods: We surveyed our institutional pathology database from 1986 through 2001 for patients with resected pathologic stage IIIA (N2) non-small cell lung cancer. Three hundred fifty-three patients were confirmed to have appropriate pathologic staging and attempted complete resection. These patients were assessed by means of univariate and multivariable analysis for factors associated with long-term survival. Stage migration was estimated by using a classification based on nodal station involvement.

Results: Median potential follow-up was 132 months. During the study period, 3and 5-year survival increased; preoperative staging improved, relatively more lobectomies and fewer pneumonectomies were performed, and multimodality treatment was used more frequently. The number of positive N2 nodal stations did not change over time $(P=.14)$. Surgical intervention alone resulted in 3-year survival of $30 \%$, and perioperative chemotherapy, radiation, or both increased 3-year survival to $38 \%(P=.004)$. Multivariable analysis showed that male sex (hazard ratio, 1.44; $95 \%$ confidence interval, $1.13-1.84 ; P=.003$ ), more than 2 positive mediastinal nodal stations (hazard ratio, 1.73; 95\% confidence interval, $1.16-2.57 ; P=$ .007), R1 or R2 resection (hazard ratio, 1.72; 95\% confidence interval, 1.22-2.41; $P=.002$ ), lower or middle lobe tumor location (hazard ratio, $1.63 ; 95 \%$ confidence interval, 1.28-2.08; $P<.001$ ), and surgical intervention alone (hazard ratio, 1.59; 95\% confidence interval, $1.23-2.04 ; P<.001$ ) were independent predictors of poor survival.

Conclusions: The use of multimodality therapy appears to contribute to improved outcomes over time in patients with resected stage IIIA (N2) non-small cell lung cancer.

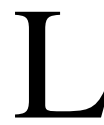
ung cancer continues to be the second-most common cancer and the most frequent cause of cancer death in the United States. ${ }^{1}$ It is estimated that approximately $10 \%$ to $18 \%$ of patients with non-small cell lung cancer (NSCLC) present with stage IIIA disease with metastases to ipsilateral mediastinal and subcarinal lymph nodes, ${ }^{2,3}$ with an expected 5-year survival of $13 \% .{ }^{4}$ Optimal treatment for this challenging group of patients remains to be defined.

Poor outcomes with surgical intervention alone in patients with stage IIIA disease have stimulated the development of multimodality regimens incorporating 


\section{Abbreviations and Acronyms \\ NSCLC $=$ non-small cell lung cancer}

chemotherapy to treat systemic micrometastases and radiation therapy to improve local control. Although a few clinical trials have shown improved survival with multimodality therapy, the effect of these interventions in a cancer center practice over time has not been extensively studied. The purpose of this study is to determine whether outcomes in resected stage IIIA (N2) NSCLC have improved over time as multimodality therapy has entered clinical practice and, if so, to ascertain what factors have brought about this improvement. Thus we examined our results in patients with resected IIIA (N2) NSCLC from 1986 through 2001, specifically examining changes in treatment approaches and patient factors over time.

\section{Methods}

\section{Patient Population}

After approval by our institutional review board, we reviewed our institutional tumor registry for patients who had surgery for NSCLC at the University of Texas MD Anderson Cancer Center during the time period of January 1986 through December 2001 $(\mathrm{n}=2861)$. We then identified patients with resected pathologic stage IIIA (N2) NSCLC. This list was cross-referenced with our departmental thoracic surgery database containing prospectively collected data from 1996 to the present. Patients were excluded if they had carcinoid, sarcomatoid, or pure small cell histology or if they were not pathologically proved to have $\mathrm{N} 2$ metastases by means of preoperative mediastinoscopy or lymph node biopsy or mediastinal lymph node dissection at the time of resection. All patients were classified according to the New International Staging System for Lung Cancer, ${ }^{4}$ irrespective of the staging system in use at the time of the operation. The charts of the remaining 353 patients who met these criteria were further reviewed to obtain clinical characteristics, including multimodality treatment received at our institution or elsewhere, demographics, surgical outcome, and survival data.

To analyze time trends in outcomes for stage IIIA lung cancer, we reviewed our data by year from 1986 through 2001. Preliminary analysis showed more frequent use of chemotherapy in the period from 1993 through 2001. Because of this, we divided the study period into an early (1986-1992) and a contemporary (19932001) era to evaluate other changes in treatment approach and changes in outcomes over time.

\section{Preoperative Assessment}

Most patients were evaluated with computed tomographic scanning of the chest (Table 1). Additional staging studies were performed at the discretion of the surgeon or oncologist. Most patients had functional evaluations to assess their ability to tolerate pulmonary resection. Cervical mediastinoscopy or anterior mediastinotomy were also performed at the discretion of the surgeon. Positron emission tomography was introduced late in the study period, and very few patients were evaluated with this modality (Table 1).

\section{Surgical Intervention}

At the time of thoracotomy, the surgeon determined the extent of lymph node sampling or dissection that was performed. In general, levels $2,4,7,8,9$, and 10 were removed during right thoracotomy, and levels $5,6,7,8,9$, and 10 were removed during left thoracotomy. The pathologist examined levels 11 and higher in the course of processing the surgical specimen. ${ }^{5}$

\section{Follow-up}

Patients were followed after resection at 1 month postoperatively, then every 6 months for 2 years, and then annually thereafter or as indicated by changes in clinical status. Chest radiographs were obtained at each follow-up visit, and further testing was performed as indicated by symptoms, signs, or abnormal chest $\mathrm{x}$-ray findings.

\section{Statistical Analysis}

Association between categorical variables was assessed by using the $\chi^{2}$ analysis or the Fisher exact test. Nonnormally distributed samples were compared with Mann-Whitney nonparametric analysis. Survival was estimated from the date of surgical intervention to the date of death or from the date of treatment initiation for patients who received induction treatment and graphically displayed by using the Kaplan-Meier method. All-cause mortality was used as the end point of primary interest. Independent predictors for survival were determined by using univariate followed by multivariable Cox regression analysis, with Wald stepwise backward elimination. The final multivariable model includes year of operation and Zubrod performance status, which were included on the basis of potential prognostic importance, even though they were not statistically significant. Patients who died perioperatively were included in all analyses to account for treatment-related effects. Data entry and analysis were performed with SPSS (Chicago, Ill) software, version 13.0.

\section{Results}

Patient demographics and outcomes by time period are listed in Table 1. Mean age increased, yet overall performance status improved from the early to the contemporary time period. There was a 2 -fold increase in use of mediastinoscopy over the study period. However, many patients did not have mediastinoscopy. This could result in misclassification of disease as p-stage IIIA, when it is in fact stage IIIB by virtue of $\mathrm{N} 3$ disease. We compared the rate of locoregional recurrence between those who had mediastinoscopy and those who did not because undiagnosed N3 disease would be expected to cause mediastinal or supraclavicular recurrence. We found no significant difference in recurrence in the mediastinum $(P=1.0)$ or the supraclavicular region $(P=.52)$. Despite increased use of mediastinoscopy and technologic improvements in the precision of computed tomographic scans, there were still a large number of patients whose disease was incorrectly staged as clinical N0 (85/159 [53.5\%] in the early time period and 
TABLE 1. Patient demographics and outcomes by time period

\begin{tabular}{|c|c|c|c|c|}
\hline Characteristic & $1986-1992, n=159$ & 1993-2001, n = 194 & Total, $\mathbf{n}=353$ & $P$ value* \\
\hline Operations/y & 22.7 & 21.6 & 22.1 & NA \\
\hline Median potential follow-up (mo) & 178.5 & 89.3 & 131.8 & NA \\
\hline Sex (\% male) & 64 & 55 & 59 & .09 \\
\hline Mean age (y) & 60.9 & 63.9 & 62.5 & .005 \\
\hline Performance status & & & & $<.001$ \\
\hline 0 & $22(14 \%)$ & $40(21 \%)$ & $62(18 \%)$ & \\
\hline 1 & $120(76 \%)$ & $151(78 \%)$ & $271(77 \%)$ & \\
\hline$\geq 2$ & $17(11 \%)$ & $3(2 \%)$ & $20(6 \%)$ & \\
\hline \multicolumn{5}{|l|}{ Staging } \\
\hline CT scan of chest & $156(98 \%)$ & $194(100 \%)$ & $350(99 \%)$ & .09 \\
\hline Mediastinoscopy & $26(16 \%)$ & $62(32 \%)$ & $88(25 \%)$ & .001 \\
\hline PET scan & 0 & $10(5 \%)$ & $10(3 \%)$ & .003 \\
\hline Histology & & & & .78 \\
\hline Squamous & $50(31 \%)$ & $59(30 \%)$ & $109(31 \%)$ & \\
\hline Adenocarcinoma & $91(57 \%)$ & $116(60 \%)$ & $207(59 \%)$ & \\
\hline Large cell & $6(4 \%)$ & $9(5 \%)$ & $15(4 \%)$ & \\
\hline Other & $12(8 \%)$ & $10(5 \%)$ & $22(6 \%)$ & \\
\hline Treatment scheme & & & & .001 \\
\hline Surgical intervention alone & $64(40 \%)$ & $52(27 \%)$ & $116(33 \%)$ & \\
\hline Surgical intervention $+\mathrm{XRT \dagger}$ & $72(45 \%)$ & $84(43 \%)$ & $156(44 \%)$ & \\
\hline Surgical intervention + chemotherapy \pm XRT & $23(15 \%)$ & $58(30 \%)$ & $81(23 \%)$ & \\
\hline Type of resection & & & & $<.001$ \\
\hline Wedge or segmentectomy & $18(11 \%)$ & $13(7 \%)$ & $31(9 \%)$ & \\
\hline Lobectomy & $86(54 \%)$ & $148(76 \%)$ & $234(66 \%)$ & \\
\hline Pneumonectomy & $55(35 \%)$ & $33(17 \%)$ & $88(25 \%)$ & \\
\hline Tumor location & & & & .95 \\
\hline Upper lobe & $79(50 \%)$ & $97(50 \%)$ & $176(50 \%)$ & \\
\hline Lower or middle lobe & $80(50 \%)$ & $97(50 \%)$ & $177(50 \%)$ & \\
\hline 30-day mortality & $6(4 \%)$ & $9(5 \%)$ & $15(4 \%)$ & .70 \\
\hline Completeness of resection§ & & & & .16 \\
\hline RO & $132(83 \%)$ & $174(90 \%)$ & $306(87 \%)$ & \\
\hline $\mathrm{R} 1$ & $23(14 \%)$ & $16(8 \%)$ & $39(11 \%)$ & \\
\hline $\mathrm{R} 2$ & $4(3 \%)$ & $4(2 \%)$ & $8(2 \%)$ & \\
\hline Survival & & & & .019 \\
\hline Median (mo) & 19.2 & 26.6 & 21.8 & \\
\hline $3-y$ & $28 \%$ & $41 \%$ & & \\
\hline $5-y$ & $18 \%$ & $25 \%$ & & \\
\hline
\end{tabular}

$C T$, Computed tomography; PET, positron emission tomography; $X R T$, radiation therapy. $* P$ value for comparison of the 2 time periods. $\dagger$ All patients in this group had postoperative radiation therapy. $\neq$ Includes the following subsets $(C=$ chemotherapy, $X=$ radiation therapy, $S=$ surgical intervention; initials listed in sequence of delivery): CS, 8 (2\%); CSC, 7 (2\%); CSCX, 8 (2\%); CSX, 27 (8\%); CXS, 3 (1\%); CXSC, 1 (0.3\%); SC, 7 (2\%); SCX, 20 (6\%). §R0 resection: removal of all detectable disease, negative tissue margins. R1 resection: all gross disease removed but tissue margins positive. R2 resection: gross residual disease after attempted resection.

92/194 [47\%] in the contemporary time period, $P=.36$ ). Significantly more patients underwent lobectomy, with fewer subanatomic resections and fewer pneumonectomies in the contemporary era.

\section{Multimodality Therapy}

There was a statistically significant increase over time in the number of patients receiving multimodality therapy, particularly in the use of chemotherapy preoperatively or postoperatively (Table 1). Chemotherapy was given in the follow- ing sequences: 38 patients treated preoperatively, 16 treated preoperatively and postoperatively, and 27 treated postoperatively. Actual treatment sequences and agents varied; however, most patients treated with chemotherapy received a platinum agent $(82.6 \%$ in the early period and $87.9 \%$ in the contemporary period, $P=.50$ ). Only 4 patients received preoperative radiation therapy (median dose, $45 \mathrm{~Gy}$ ). One hundred fifty-six patients underwent radiation therapy postoperatively (median dose, 55 Gy). 


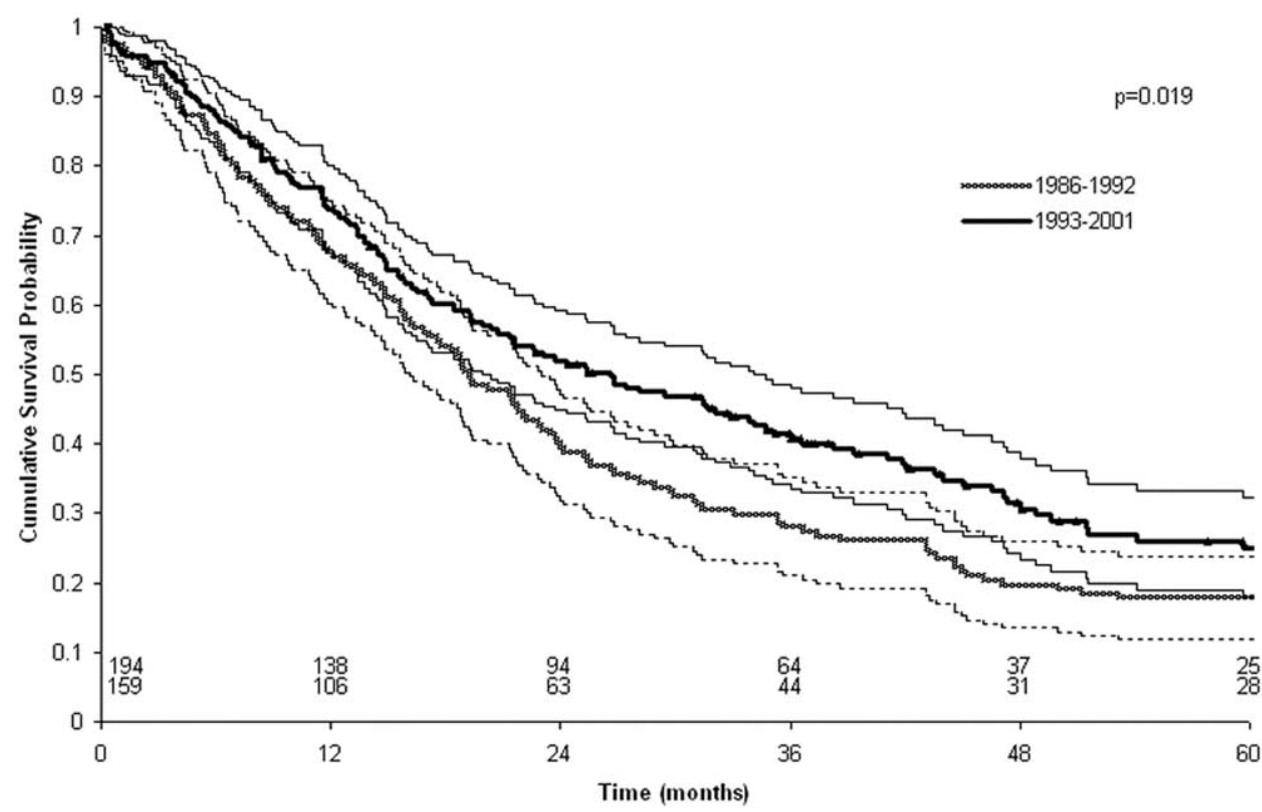

Figure 1. Survival by time period comparing 159 patients from 1986 through 1992 (early era) and 194 patients from 1993 through 2001 (contemporary era). Ninety-five percent confidence intervals are displayed. Solid lines, 1993 through 2001; dashed lines, 1986 through 1992.

\section{Treatment Outcomes}

Overall survival improved significantly $(P=.019)$ over the course of the study (Figure 1 and Table 1). Perioperative mortality was unchanged between the 2 time periods. There was an increased frequency of complete resection, but this did not reach statistical significance $(P=.16)$. Univariate followed by multivariable analysis for survival was performed to identify factors leading to improved survival (Table 2). Variables included in the model are listed in the table footnote. Female sex, upper lobe tumor location, any additional chemotherapy or radiation (compared with surgical intervention alone), complete resection, and involvement of only one N2 nodal station were all highly significant independent predictors of improved survival.

These prognostic factors were further examined with respect to long-term survival. Factors related to lymph node staging and their changes over time are shown in Table 3. There was no difference in the number of nodes or the number of stations sampled over time by means of thoracotomy. An average of $1.4 \mathrm{~N} 2$ stations were involved with tumor for each patient, and this was unchanged over the study period. On the basis of these results, pathologic stage migration does not appear to have occurred over the course of the study. There were more patients with extracapsular extension of tumor in at least one lymph node in the earlier time period $(P=.044)$; however, this was not an independent predictor of survival by multivariable analysis (Table 2). Survival outcome stratified by number of $\mathrm{N} 2$ stations with metastatic cancer are shown in Figure 2. Median survival was statistically significantly improved $(P<.001)$ when only 1 station was involved (1 station, 25.3 months; 2 stations, 16.8 months; $>2$ stations, 15.5 months). Of note, TNM stage distribution was unchanged over time $(P=.16)$ and similar by treatment group $(P=.15)$, and therefore these improvements are unlikely to be due to changes in $\mathrm{T}$ status. In addition, patients with left upper lobe tumors and nodal involvement of levels 5,6 , or both $(\mathrm{n}=21)$ were evenly distributed between time periods (early, $\mathrm{n}=10$; contemporary, $\mathrm{n}=11 ; P=.81$ ), and their survival (median, 23.8 months) did not differ significantly compared with that of the rest of the patients $(\mathrm{n}=332$; median, 21.6 months; $P=.70$ ).

Survival outcomes by treatment group are displayed in Figure 3. Median survival improved significantly from 15.9 months for surgical intervention alone to 25.3 months with the addition of multimodality therapy; 3 - and 5-year survival rates increased from $30 \%$ and $17 \%$ to $38 \%$ and $24 \%$, respectively $(P=.004)$. To further evaluate the effect of chemotherapy, we compared patients who received perioperative chemotherapy with those who had resection alone (Figure E1); median survival increased to 31.1 months when patients received chemotherapy compared with resection alone (15.9 months, $P=.004)$. We compared resection alone with resection followed by radiation therapy (without chemotherapy, Figure E2); median survival increased from 
TABLE 2. Multivariable analysis for survival

\begin{tabular}{|c|c|c|c|c|}
\hline & Frequency & HR & $\begin{array}{l}95 \% \mathrm{CI} \\
\text { for } \mathrm{HR}\end{array}$ & $P$ value \\
\hline Sex & & & & .01 \\
\hline Female (reference) & 144 & 1.0 & & \\
\hline Male & 209 & 1.38 & $1.08-1.77$ & \\
\hline Tumor lobe & & & & $<.001$ \\
\hline Upper (reference) & 176 & 1.0 & & \\
\hline Lower or middle & 177 & 1.68 & $1.31-2.15$ & \\
\hline Treatment & & & & $<.001$ \\
\hline $\begin{array}{l}\text { Surgical intervention } \\
\text { only (reference) }\end{array}$ & 116 & 1.0 & & \\
\hline $\begin{array}{c}\text { Surgical intervention }+ \\
\text { postoperative XRT }\end{array}$ & 156 & 0.65 & $0.49-0.85$ & .002 \\
\hline $\begin{array}{l}\text { Surgical intervention }+ \\
\text { chemotherapy } \pm \text { XRT }\end{array}$ & 81 & 0.68 & $0.48-0.97$ & .03 \\
\hline Extent of resection & & & & .004 \\
\hline RO (reference) & 306 & 1.0 & & \\
\hline $\mathrm{R} 1-\mathrm{R} 2$ & 47 & 1.66 & $1.17-2.34$ & \\
\hline Positive N2 nodal stations & & & & .002 \\
\hline 1 (reference) & 239 & 1.0 & & \\
\hline 2 & 78 & 1.66 & $1.25-2.22$ & .001 \\
\hline$>2$ & 33 & 1.60 & $1.06-2.41$ & .03 \\
\hline 0 (downstaged) & 3 & 0.79 & $0.19-3.26$ & .74 \\
\hline Year of operation* & 353 & 0.98 & $0.95-1.005$ & .10 \\
\hline Zubrod performance status & & & & .30 \\
\hline 0 (reference) & 62 & 1.0 & & \\
\hline 1 & 271 & 0.91 & $0.65-1.26$ & .57 \\
\hline$\geq 2$ & 20 & 1.32 & $0.75-2.31$ & .33 \\
\hline
\end{tabular}

Other potentially prognostic variables included in univariate analysis that did not achieve statistical significance on multivariable analysis are tumor side, type of resection, tumor histology, age, and extracapsular nodal extension. $H R$, Hazard ratio; $C l$, confidence interval; $X R T$, radiation therapy. *Analyzed as a continuous variable.

15.9 months to 23.1 months $(P=.035)$. We compared survival with resection alone over time to ascertain whether the natural history of the disease had changed over the 15-year period; no difference was identified $(P=.217)$. Figure E3 shows survival by extent of resection. Patients with R0 resection had a median survival of 23.8 months compared with 14.4 months for those with R1 or R2 resection $(P=.001)$.

\section{Discussion}

By evaluating our results over time, we have shown that outcomes in patients with p-stage IIIA (N2) NSCLC have improved over the study period. The independent predictors of survival, ie, sex, completeness of resection, tumor lobe location, and extent of $\mathrm{N} 2$ disease have previously been identified as prognostic factors ${ }^{3,6,7}$ and were confirmed in our cohort. Moreover, we have shown that the addition of chemotherapy or radiation therapy to resection for patients with p-stage IIIA (N2) disease independently predicted enhanced survival. When we compared patients who had preoperative or postoperative chemotherapy with those treated with surgical intervention alone, we found the survival benefit persisted and was even more marked. Further analysis of subgroups of chemotherapy-treated subjects was not performed because of the small sample size and heterogeneity of these subgroups (Table 1, footnote).

Surprisingly, the type of resection did not affect survival on univariate or multivariable analysis. Others have reported increased mortality rates associated with pneumonectomy after induction therapy. ${ }^{8}$ Of 89 pneumonectomies in our cohort, perioperative mortality was $9 \%$; there was only one death in 13 patients who had preoperative therapy followed by pneumonectomy $(7.7 \%$ mortality in this subset).

We considered the possibility of stage migration as an explanation for the survival improvement observed. This could result from categorization of patients with N3 or M1 disease as having IIIA cancer because of inaccurate staging in the early era, resulting in diminished survival for stage IIIA cancer compared with the contemporary era with more accurate staging. When we examined the extent of lymph node dissection and compared these results across time periods, no differences were noted, suggesting that stage migration did not occur. In addition, if staging accuracy had changed markedly over the course of this study, one would expect the outcomes of patients treated with surgical intervention alone to improve in the contemporary cohort; however, no differences were found in survival. Stage migration might be contributory to the improved survival we observed over time, but we were unable to demonstrate its occurrence.

Alterations in survival over time might occur as a result of inclusion of an increased proportion of lower-risk patients (in terms of tumor-related factors) in the contemporary time period. Patients with left upper lobe tumors and involvement of only level 5 or 6 nodes have been shown in several studies to have improved prognosis, behaving more like N1 disease. ${ }^{6,9-11}$ There were 21 patients in our study who met this criterion, and they were evenly distributed in the 2 time periods. Furthermore, there was no difference when comparing their survival with that of the rest of the cohort. This supports previous findings published by Watanabe and colleagues. ${ }^{12}$

The question remains as to what is the best approach to patients with IIIA (N2) disease in a practice setting. That is, what approach offers maximal effectiveness (ie, "results achieved in the actual practice of healthcare with typical patients and providers" ${ }^{\prime 3}$ ). Our study offers insight into what can be accomplished when multimodality care is applied in a cancer center practice. An extensive research effort in multimodality therapy has been mounted over the last 15 to 20 years, with mixed success in improving survival. One of the first modalities used in the surgical adju- 
TABLE 3. Lymph node data at thoracotomy by time period

\begin{tabular}{|c|c|c|c|c|}
\hline Characteristic & 1986-1992 & 1993-2001 & Total & $P$ value* \\
\hline \multicolumn{5}{|l|}{ Total no. of nodes retrieved per patient, mean } \\
\hline$(95 \% \mathrm{Cl}) ;$ median & $15.7(14.3-17.0) ; 14.0$ & $16.2(15.6-17.3) ; 14.5$ & $15.9(15.1-16.8) ; 14.0$ & $.56 \ddagger$ \\
\hline \multicolumn{5}{|l|}{ No. of nodal stations sampled per patient, mean } \\
\hline$(95 \% \mathrm{Cl}) ;$ median & $4.5(4.3-4.7) ; 5.0$ & $4.6(4.4-4.7) ; 5.0$ & $4.5(4.4-4.7) ; 5.0$ & $.58 \ddagger$ \\
\hline N1 & $1.5(1.3-1.6) ; 1.0$ & $1.6(1.5-1.7) ; 2.0$ & $1.5(1.4-1.6) ; 1.0$ & $.16 \ddagger$ \\
\hline N2 & $3.1(2.9-3.2) ; 3.0$ & $3.0(2.9-3.1) ; 3.0$ & $3.0(2.9-3.1) ; 3.0$ & $.68 \ddagger$ \\
\hline N3\| & $0.35(0.09-0.6) ; 0$ & $0.71(0.54-0.88) ; 1.0$ & $0.60(0.46-0.75) ; 0$ & $.01 \ddagger$ \\
\hline \multicolumn{5}{|l|}{ Positive N2 stations per patient, mean $(95 \% \mathrm{CI})$; } \\
\hline median & $1.5(1.4-1.6) ; 1.0$ & $1.4(1.3-1.5) ; 1.0$ & $1.4(1.3-1.5) ; 1.0$ & $.14 \ddagger$ \\
\hline No N2 diseaset & $1(0.1 \%)$ & $2(0.1 \%)$ & $3(0.1 \%)$ & NS§ \\
\hline Single-level N2 disease & $104(66 \%)$ & $135(70 \%)$ & $239(68 \%)$ & $.31 \S$ \\
\hline Two levels of N2 disease & $35(22 \%)$ & $43(22 \%)$ & $78(22 \%)$ & \\
\hline$>2$ levels of $\mathrm{N} 2$ disease & $19(12 \%)$ & $14(7 \%)$ & $33(9 \%)$ & \\
\hline Nodal extracapsular invasion present, n (\%) & $41(26)$ & $33(17)$ & $74(21)$ & $.04 \S$ \\
\hline
\end{tabular}

$\mathrm{Cl}$, Confidence interval. *P value for comparison of the 2 time periods. $†$ Three patients had $\mathrm{N} 2$ disease at mediastinoscopy. After induction chemotherapy, all N2 nodal disease had resolved. The final pathologic stages were T1 N0 M0, T1 N1 M0, and T2 N1 M0. $\$ P$ value from Mann-Whitney nonparametric analysis. $\S P$ value from $\chi^{2}$ analysis. $\|$ From patients who had mediastinoscopy: $\mathrm{n}=26$ in the 1986 through 1992 time period and $\mathrm{n}=62$ in the 1993 through 2001 time period.

vant setting was external beam radiation therapy. Several studies have not shown any enhancement of survival for pN2 disease but have shown decreased rates of local recurrence. ${ }^{14-16}$ Surprisingly, our results show that postoperative

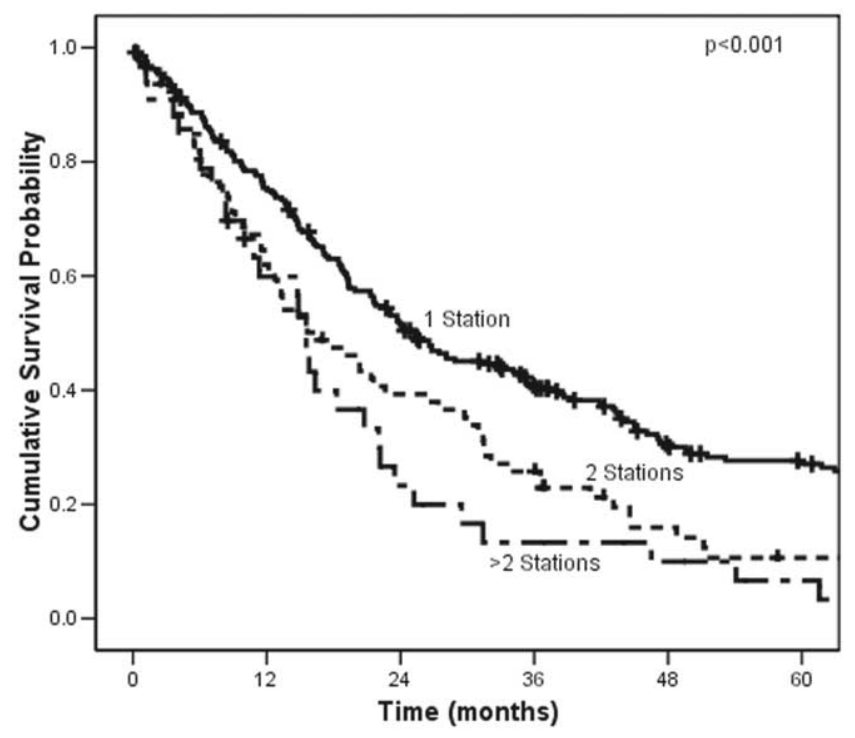

Figure 2. Survival by number of N2 nodal stations containing tumor (1 vs 2 vs >2). Two hundred thirty-nine patients had single-station N2 involvement, 78 had 2 N2 stations involved, and 33 had more than 2 N2 stations involved with tumor.

Number at risk

\begin{tabular}{lcccccc}
\hline & $0 \mathrm{mo}$ & $12 \mathrm{mo}$ & $24 \mathrm{mo}$ & $36 \mathrm{mo}$ & $48 \mathrm{mo}$ & $60 \mathrm{mo}$ \\
1 station & 239 & 177 & 119 & 82 & 53 & 43 \\
2 stations & 78 & 47 & 29 & 19 & 9 & 5 \\
$>2$ stations & 33 & 18 & 7 & 4 & 3 & 2 \\
\hline
\end{tabular}

radiation therapy was associated with improved survival relative to surgical intervention alone. The study by Keller and associates ${ }^{17}$ also documented favorable survival rates for surgical intervention followed by radiation therapy (39 months), which were much higher than expected with surgical intervention alone, but this study included patients with stage II and T3 N1 disease. There is general agreement that adjuvant radiation therapy is an appropriate therapeutic alternative to observation in patients with p-stage IIIA (N2) disease to decrease local recurrence, whereas a definitive answer regarding survival benefit remains to be determined.

Induction chemotherapy versus surgical intervention alone has been tested in 4 randomized controlled trials for stage IIIA NSCLC. Two trials demonstrated survival benefit with chemotherapy, ${ }^{18-21}$ and 2 other studies did not show a difference. ${ }^{22,23}$ The earlier trials included patients with T3 N0 M0 disease, and all 4 studies involved small numbers of patients (27-62 patients per study), limiting the power to show a difference between the study arms. A recent study with larger enrollment (355 patients) evaluated stages I through IIIA NSCLC ${ }^{24}$ and showed survival improvement in stages I and II disease, but subset analysis was unable to demonstrate an advantage to induction chemotherapy in patients with IIIA disease (hazard ratio, 1.04; 95\% confidence interval, 0.68-1.60).

When N2 disease is not discovered preoperatively, consideration should be given to adjuvant chemotherapy. However, chemotherapy is often not well tolerated after lung resection. ${ }^{25}$ Many trials report administration of only $60 \%$ of the intended dose. ${ }^{26}$ Randomized trials of adjuvant chemotherapy in the 1990s did not show improvement in survival; however, a meta-analysis looking at platinum-based regimens showed a trend toward survival benefit, ${ }^{27}$ which 


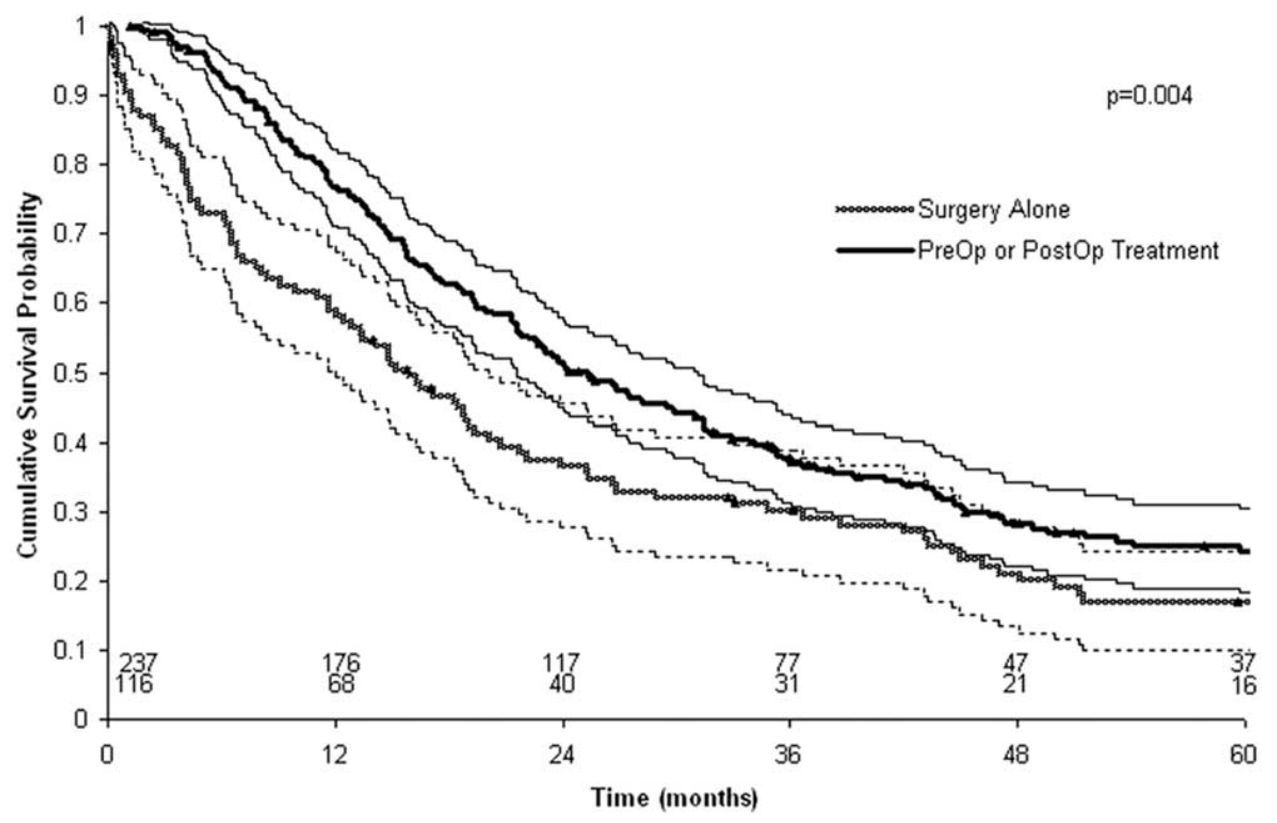

Figure 3. Survival by treatment group (surgical intervention alone $[n=116]$ vs preoperative or postoperative treatment $[n=237]$ ). Ninety-five percent confidence intervals are displayed. Solid lines, preoperative or postoperative treatment; dashed lines, surgical intervention alone.

subsequently stimulated the performance of several multicenter trials. $^{28-31}$ The recent IALT study ${ }^{28}$ showed an overall survival benefit for adjuvant chemotherapy that was greatest for patients with stage III disease, whereas the ALPI study ${ }^{29}$ was unable to achieve a significant survival advantage. Two other multicenter trials ${ }^{30,31}$ have shown survival advantages with adjuvant chemotherapy in earlystage NSCLC. These trial results suggest that adjuvant chemotherapy should be considered in all patients ( $p$-stage IB-IIIA) as a standard of care. Questions concerning the timing of chemotherapy in relation to tumor resection remain. Our standard practice is to recommend induction chemotherapy for patients with stage IIIA disease, but further clinical investigations into the timing of chemotherapy are warranted.

Although this study describes the evolution of outcomes for patients with p-stage IIIA (N2) NSCLC and the positive effect of multimodality therapy, important limitations remain. Our study is retrospective. Because treatment was assigned on the basis of clinician judgment, selection bias is of concern; we attempted to minimize this bias by controlling for other prognostic factors in multivariable analysis.

Second, because all patients with lung cancer presenting to our institution are not enrolled in a study or entered in a database, it is difficult to know the true denominator of patients with IIIA disease. We chose to use pathologic staging for identifying IIIA (N2) disease because of the inaccuracy of clinical staging, but this does create pitfalls.
We are likely to miss 2 main groups: those patients with N2 metastases who were downstaged by induction therapy and did not have pathologic evidence of N2 disease at resection, and those who were considered inoperable because of physiologic status or bulky N2 disease. Only 3 patients were identified in our study who had resolution or decrease of their mediastinal nodal disease (documented by mediastinoscopy before treatment) after induction chemotherapy. These 3 patients have enjoyed a median disease-free survival of 8.6 years. Other patients with enlarged mediastinal lymph nodes who did not have pretreatment histologic confirmation of $\mathrm{N} 2$ disease but were downstaged by induction treatment were excluded from the study. This would bias our results by excluding the subset of patients with IIIA disease who had a good response to induction therapy, which would tend to minimize the differences observed between the group undergoing resection alone versus the multimodality therapy group. Because we found a significant survival improvement with multimodality therapy, the true survival advantage might indeed be greater than we have presented here.

In conclusion, we have demonstrated that survival after resection of patients with stage IIIA (N2) NSCLC disease has increased in the more recent patient study group. Our results confirm improved prognosis with female sex, upper lobe tumor location, $\mathrm{R} 0$ resection, involvement of only a single N2 nodal station, and addition of multimodality therapy to resection. The distribution of these favorable prog- 
nostic factors in the 2 time periods was similar, with the exception of multimodality therapy, which was used more extensively in the contemporary era. Thus the survival improvement we observed appears to be associated with increased use of multimodality therapy.

We thank B. Nebiyou Bekele, PhD, Department of Biostatistics and Applied Mathematics, University of Texas, MD Anderson Cancer Center, for statistical review of the manuscript. We are also greatly indebted to Marcelo Dolormente, RN, Rhodette Francisco, RN, Faye Martin, RN, and Arcenio Sarabia, RN, for their assistance with data collection.

\section{References}

1. Jemal A, Murray T, Ward E, Samuels A, Tiwari RC, Ghafoor A, et al. Cancer statistics, 2005. CA Cancer J Clin. 2005;55:10-30.

2. Robinson LA, Wagner H Jr, Ruckdeschel JC, American College of Chest Physicians. Treatment of stage IIIA non-small cell lung cancer. Chest. 2003;123(suppl):202S-20S.

3. van Rens MT, de la Riviere AB, Elbers HR, Den Bosch JM. Prognostic assessment of 2,361 patients who underwent pulmonary resection for non-small cell lung cancer, stage I, II, and IIIA. Chest. 2000;117: 374-9.

4. Mountain CF. Revisions in the International System for Staging Lung Cancer. Chest. 1997;111:1710-7.

5. Naruke T, Suemasu K, Ishikawa S. Lymph node mapping and curability at various levels of metastasis in resected lung cancer. $J$ Thorac Cardiovasc Surg. 1978;76:832-9.

6. Inoue M, Sawabata N, Takeda S, Ohta M, Ohno Y, Maeda H. Results of surgical intervention for p-stage IIIA (N2) non-small cell lung cancer: acceptable prognosis predicted by complete resection in patients with single N2 disease with primary tumor in the upper lobe. J Thorac Cardiovasc Surg. 2004;127:1100-6.

7. Okada M, Nishio W, Sakamoto T, Uchino K, Yuki T, Nakagawa A, et al. Evolution of surgical outcomes for nonsmall cell lung cancer: time trends in 1465 consecutive patients undergoing complete resection. Ann Thorac Surg. 2004;77:1926-30.

8. Martin J, Ginsberg RJ, Abolhoda A, Bains MS, Downey RJ, Korst R, et al. Morbidity and mortality after neoadjuvant therapy for lung cancer: the risks of right pneumonectomy. Ann Thorac Surg. 2001;72: 1149-54.

9. Keller SM, Vangel MG, Wagner H, Schiller JH, Herskovic A, Komaki $\mathrm{R}$, et al. Prolonged survival in patients with resected non-small cell lung cancer and single-level N2 disease. J Thorac Cardiovasc Surg. 2004;128:130-7.

10. Miller DL, McManus KG, Allen MS, Ilstrup DM, Deschamps C, Trastek VF, et al. Results of surgical resection in patients with N2 non-small cell lung cancer. Ann Thorac Surg. 1994;57:1095-100.

11. Patterson GA, Piazza D, Pearson FG, Todd TR, Ginsberg RJ, Goldberg M, et al. Significance of metastatic disease in subaortic lymph nodes. Ann Thorac Surg. 1987;43:155-9.

12. Watanabe Y, Shimizu J, Oda M, Hayashi Y, Watanabe S, Tatsuzawa $\mathrm{Y}$, et al. Aggressive surgical intervention in N2 non-small cell cancer of the lung. Ann Thorac Surg. 1991;51:253-61.

13. Aday LA, Begley CE, Lairson DR, Balkrishnan R. Effectiveness: concepts and methods. Evaluating the healthcare system: effectiveness, efficiency, and equity. Chicago, Ill: Health Administration Press; 2004. p. 57-91.

14. The Lung Cancer Study Group. Effects of postoperative mediastinal radiation on completely resected stage II and stage III epidermoid cancer of the lung. N Engl J Med. 1986;315:1377-81.

15. PORT Meta-analysis Trialists Group. Postoperative radiotherapy in non-small-cell lung cancer: systematic review and meta-analysis of individual patient data from nine randomised controlled trials. Lancet. 1998;352:257-63.

16. Mayer R, Smolle-Juettner FM, Szolar D, Stuecklschweiger GF, Quehenberger F, Friehs G, et al. Postoperative radiotherapy in radically resected non-small cell lung cancer. Chest. 1997;112:954-9.
17. Keller SM, Adak S, Wagner H, Herskovic A, Komaki R, Brooks BJ, et al. A randomized trial of postoperative adjuvant therapy in patients with completely resected stage II or IIIA non-small-cell lung cancer. Eastern Cooperative Oncology Group. N Engl J Med. 2000;343:1217-22.

18. Rosell R, Gomez-Codina J, Camps C, Maestre J, Padille J, Canto A, et al. A randomized trial comparing preoperative chemotherapy plus surgery with surgery alone in patients with non-small-cell lung cancer. N Engl J Med. 1994;330:153-8.

19. Rosell R, Gomez-Codina J, Camps C, Javier Sanchez J, Maestre J, Padilla J, et al. Preresectional chemotherapy in stage IIIA non-smallcell lung cancer: a 7-year assessment of a randomized controlled trial. Lung Cancer. 1999;26:7-14.

20. Roth JA, Fossella F, Komaki R, Ryan MB, Putnam JB Jr, Lee JS, et al. A randomized trial comparing perioperative chemotherapy and surgery with surgery alone in resectable stage IIIA non-small-cell lung cancer. J Natl Cancer Inst. 1994;86:673-80.

21. Roth JA, Atkinson EN, Fossella F, Komaki R, Bernadette Ryan M, Putnam JB Jr, et al. Long-term follow-up of patients enrolled in a randomized trial comparing perioperative chemotherapy and surgery with surgery alone in resectable stage IIIA non-small-cell lung cancer. Lung Cancer. 1998;21:1-6.

22. Nagai K, Tsuchiya R, Mori T, Tada H, Ichinose Y, Koike T, et al. A randomized trial comparing induction chemotherapy followed by surgery with surgery alone for patients with stage IIIA N2 non-small cell lung cancer (JCOG 9209). J Thorac Cardiovasc Surg. 2003;125: 254-60.

23. Pass HI, Pogrebniak HW, Steinberg SM, Mulshine J, Minna J. Randomized trial of neoadjuvant therapy for lung cancer: interim analysis. Ann Thorac Surg. 1992;53:992-8.

24. Depierre A, Milleron B, Moro-Sibilot D, Chevret S, Quoix E, Lebeau $\mathrm{B}$, et al. Preoperative chemotherapy followed by surgery compared with primary surgery in resectable stage I (except T1N0), II, and IIIa non-small-cell lung cancer. $J$ Clin Oncol. 2002;20:247-53.

25. Pisters KM, Ginsberg RJ, Giroux DJ, Putnam JB Jr, Kris MG, Johnson $\mathrm{DH}$, et al. Induction chemotherapy before surgery for early-stage lung cancer: a novel approach. Bimodality Lung Oncology Team. J Thorac Cardiovasc Surg. 2000;119:429-39.

26. Pisters KM. Combined modality therapy of early stage nonsmall cell lung cancer. Respir Care Clin N Am. 2003;9:191-205.

27. Non-small Cell Lung Cancer Collaborative Group. Chemotherapy in non-small cell lung cancer: a meta-analysis using updated data on individual patients from 52 randomised clinical trials. BMJ. 1995;311: 899-909.

28. Arriagada R, Bergman B, Dunant A, Le Chevalier T, Pignon JP, Vansteenkiste $\mathrm{J}$, et al. Cisplatin-based adjuvant chemotherapy in patients with completely resected non-small-cell lung cancer. $N$ Engl J Med. 2004;350:351-60.

29. Scagliotti GV, Fossati R, Torri V, Crino L, Giaccone G, Silvano G, et al. Randomized study of adjuvant chemotherapy for completely resected stage I, II, or IIIA non-small-cell lung cancer. J Natl Cancer Inst. 2003;95:1453-61.

30. Strauss GM, Herndon J, Maddaus MA, Johnstone DW, Johnson EA, Watson DM, et al. Randomized Clinical Trial of adjuvant chemotherapy with paclitaxel and carboplatin following resection in stage IB non-small cell lung cancer (NSCLC): report of Cancer and Leukemia Group B (CALGB) Protocol 9633. J Clin Oncol. 2004;22(suppl):7019.

31. Winton TL, Livingston R, Johnson D, Rigas J, Cormier Y, Butts C, et al. A prospective randomized trial of adjuvant vinorelbine (VIN) and cisplatin (CIS) in completely resected Stage IB and II non-small cell lung cancer (NSCLC) Intergroup JBR.10. J Clin Oncol. 2004; 22(suppl):7018.

\section{Discussion}

Dr Valerie W. Rusch (New York, NY). This excellent analysis of the factors that influence the outcome of patients with stage IIIA N2 non-small cell lung cancer (NSCLC) who undergo surgical resection confirms several important findings that have been identified in previous retrospective studies and in clinical trials with this group of patients, namely that overall survival is influenced by 
patient sex, by tumor location, by the completeness of resection, and by the extent of nodal disease.

The favorable effect of chemotherapy on survival is consistent with 3 previous small randomized trials that showed improved outcome with induction chemotherapy and more recent large randomized trials that have shown improved outcome with adjuvant chemotherapy. These findings support the notion that combined modality therapy is now the standard of care for patients with stage IIIA NSCLC.

Other studies have also found improving outcomes in stage IIIA NSCLCs treated in a multimodality manner. For instance, an improvement in overall survival has been observed in the North American randomized intergroup trial for stage IIIA lung cancers, the so-called intergroup trial 0139, a trial that compared induction chemoradiotherapy plus surgical intervention with high-dose chemoradiotherapy without surgical intervention. Relative to the phase II trial that preceded it, the SWOG 8805 trial, which offered patients the same induction therapy, the overall survival in both arms of the 0139 trial has been considerably better, approximately $30 \%$ at 5 years.

During the past decade, there have been improvements in staging that, of course, affect patient selection for surgical intervention. We have also seen the development of better tolerated and more effective chemotherapy regimens and increasing expertise in the delivery of multimodality treatment. In addition, there has been an ongoing shift in the sex distribution of our lung cancer patient population with a steadily increasing proportion of women. Because female sex has been consistently identified as a favorable prognostic factor in all major lung cancer trials, this population shift alone probably accounts for some of the improvement in survival, even though it was not identified as the dominant factor influencing survival over time in this study from MD Anderson. It is important that we bear these issues in mind as we perform and analyze future studies in this group of patients with lung cancer.

I think that all thoracic surgeons intuitively understand why pathologically complete or R0 resection and single versus multilevel N2 disease affect survival. However, I would appreciate you commenting further on several aspects of your study.

Do you have any insight as to why patients who have middle or lower lobe tumors have a worse prognosis?

Second, other studies, including our own from Memorial Sloan-Kettering and the intergroup 0139 trial, have reported a high operative mortality for pneumonectomies after induction therapy, especially right pneumonectomies. Did you analyze right versus left pneumonectomies, and do you have any insight as to why you did not observe this particularly high operative mortality in your study?

Third, the multimodality therapy given in your study was predominantly adjuvant postoperative radiation. In light of other studies that have failed to show a survival benefit and perhaps even a detrimental effect on survival from adjuvant radiation, have you modified your approach to treatment? What do you consider the preferred type and sequence of multimodality therapy and why?

Finally, although the use of mediastinoscopy has increased at MD Anderson during this study, I noted that only one third of patients underwent mediastinoscopy during the latter part of the study, and only $5 \%$ had a positron emission tomographic scan performed. Could you perhaps comment on how your analysis has affected your use of these 2 staging modalities in the approach to multimodality therapy.

Thank you for the privilege of allowing me to comment on this excellent article.

Dr Martin. Thank you for your comments, Dr Rusch. Your first question as to why patients with lower or middle lobe tumor resection have a worse prognosis is a good question, but I cannot answer that from our study.

In terms of our operative mortality for pneumonectomies, we did look at this because of the publication from your institution, and overall, in our study there were 89 pneumonectomies, and the mortality rate for all patients undergoing pneumonectomy in our study was $9 \%$. We did look at the patients who had induction therapy followed by a pneumonectomy, and there were only 13 who met this criterion. There was one death in that group, leading to a mortality rate of $7.7 \%$. Because of the very small size of that sample, we did not compare right versus left, but again, our mortality was not as high. It might be that there were different combinations of chemotherapy used that might have affected the pulmonary morbidity and mortality, but we do not have a great explanation for why that was different.

As far as our use of adjuvant postoperative radiation therapy, we were surprised by our results that radiation itself in addition to surgical intervention did yield a better survival. The median survival was 23 months compared with 15.9 months with surgical intervention alone, and this was a novel finding. Other studies, including the PORT trial, have shown potentially lower rates of local recurrence but no definite survival benefits. I think this is something that does need to be studied further. We have not changed our use of adjuvant therapy. We still use it fairly routinely for patients with N2 disease on final pathology if they have a good performance status.

As for our ideal sequence of treatment at this point in time, it is ideal to identify patients with $\mathrm{N} 2$ disease before resection, in which case we would prefer to give induction chemotherapy followed by surgical intervention. If there is residual N2 disease at the time of the operation, we would treat with postoperative radiation therapy. In patients for whom we cannot identify the N2 disease preoperatively, we would give consideration for chemotherapy postoperatively.

As far as our mediastinoscopy rates, only $32 \%$ of our patients had mediastinoscopy in the contemporary era. However, looking at the clinical stages of our patients in that era, $50 \%$ were clinically N0 and another $15 \%$ were clinically N1, which leaves about $35 \%$ that were clinically $\mathrm{N} 2$, and our rate of mediastinoscopy was approximately $32 \%$. Therefore we were doing mediastinoscopies on most patients with clinical N2 disease.

As far as positron emission tomographic scan use, that was a fairly new modality and just came into use in the last couple of years, and our study period ended in 2001. Therefore only 10 patients in our total study time had a positron emission tomographic scan. Because of this, I cannot comment on our use of that in the study, but we are using it on almost all patients at this point in time.

Dr Frank Detterbeck (Chapel Hill, NC). You have analyzed patients on the basis of a variable that you really know postoperatively, namely pathologic $\mathrm{N} 2$ disease. I always find it a little bit difficult to take that sort of data and then apply it to a new set of 
patients about whom I do not have that information yet. Therefore I was wondering whether you could characterize the population a little bit more on the basis of preoperative variables. You started to hint at that. How many patients had clinically staged N0 or N1 disease? How many patients had a preoperative mediastinoscopy that demonstrated N2 disease and yet went on to resection anyway versus patients who had a negative mediastinoscopy but then had an incidental $\mathrm{N} 2$ disease? That would help me in applying this prospectively.

Dr Martin. Yes, it is difficult to draw conclusions from our pathologic N2 stage. The reason we chose to use that as a criteria was that the clinical staging is so unreliable, and therefore to be certain we were dealing with patients with IIIA N2 disease, we chose to use pathologic staging as our inclusion criteria. As I mentioned, the distribution of clinical staging was actually unchanged over time. There were about $50 \%$ who had clinical N0 disease in both eras and another $15 \%$ or so who had clinical N1 disease.

As far as the number of patients who had mediastinoscopyconfirmed N2 disease, I do not have that figure available, but our approach was that as long as the patient did not have bulky N2 disease, we proceeded with resection in hopes of treating the patients postoperatively with adjuvant therapy.

Dr Mark J. Krasna (Baltimore, Md). Linda, that was an excellent presentation. I have just one specific question. If you are going to use mediastinoscopy on patients to determine IIIA disease before treatment, one of the findings from the last several years' series, both the Brigham and our place, is that persistent positive mediastinal disease is a poor indicator. In other words, mediastinal clearance on its own might be a very important prognosticator. Can you perhaps comment on how you and your group will use this in the future now that you are going to hopefully use multimodality therapy? Thank you.

Dr Martin. A couple of things. First of all, we did have 3 patients in our study who had a mediastinoscopy showing N2 disease. They then had induction therapy, and the final pathology showed complete clearance of the N2 nodes. That was only 3 patients out of our entire group. Those patients did have a much longer survival, but it was such a small number that it is hard to compare them with the rest.

Definitely, persistent nodal disease is a bad prognostic indicator, but our study consisted entirely of patients with N2 disease at the time of resection, and we believe that we achieved reasonably good survival results given that circumstance. Again, if we can identify the N2 disease beforehand and treat it, that is the best possible situation, but even when we cannot, we still think we can achieve reasonable results with resection followed by adjuvant treatment.

Dr Stephen D. Cassivi (Rochester, Minn). Linda, that was a great presentation, and I commend you for the work you have done. My question to you with regard to multimodality therapy is as follows. I think we all have the inclination that that is an important part of the treatment for patients with this stage of disease. My question to you is this: Because of the nature of your retrospective study, I wonder whether some of the effect that you are attributing to multimodality therapy is, however, due to perhaps a bit of selection bias because most of your patients who got multimodality therapy got adjuvant radiation therapy, and I wonder whether there was a selection bias for those patients who were more likely to tolerate such a therapy, and therefore those who would not be likely to tolerate it were in the group that did not get it and had worse survival?

Dr Martin. Thank you. Certainly there could be selection bias. It is very difficult to determine how these decisions were made in a retrospective review, and there might be patients who had induction therapy and had a poor performance status and were not treated with surgical intervention or patients with bulky N2 disease who did not undergo resection, and therefore they did not show up in our patient population. Therefore there could be patient selection, but I cannot be certain to what extent that occurred. 


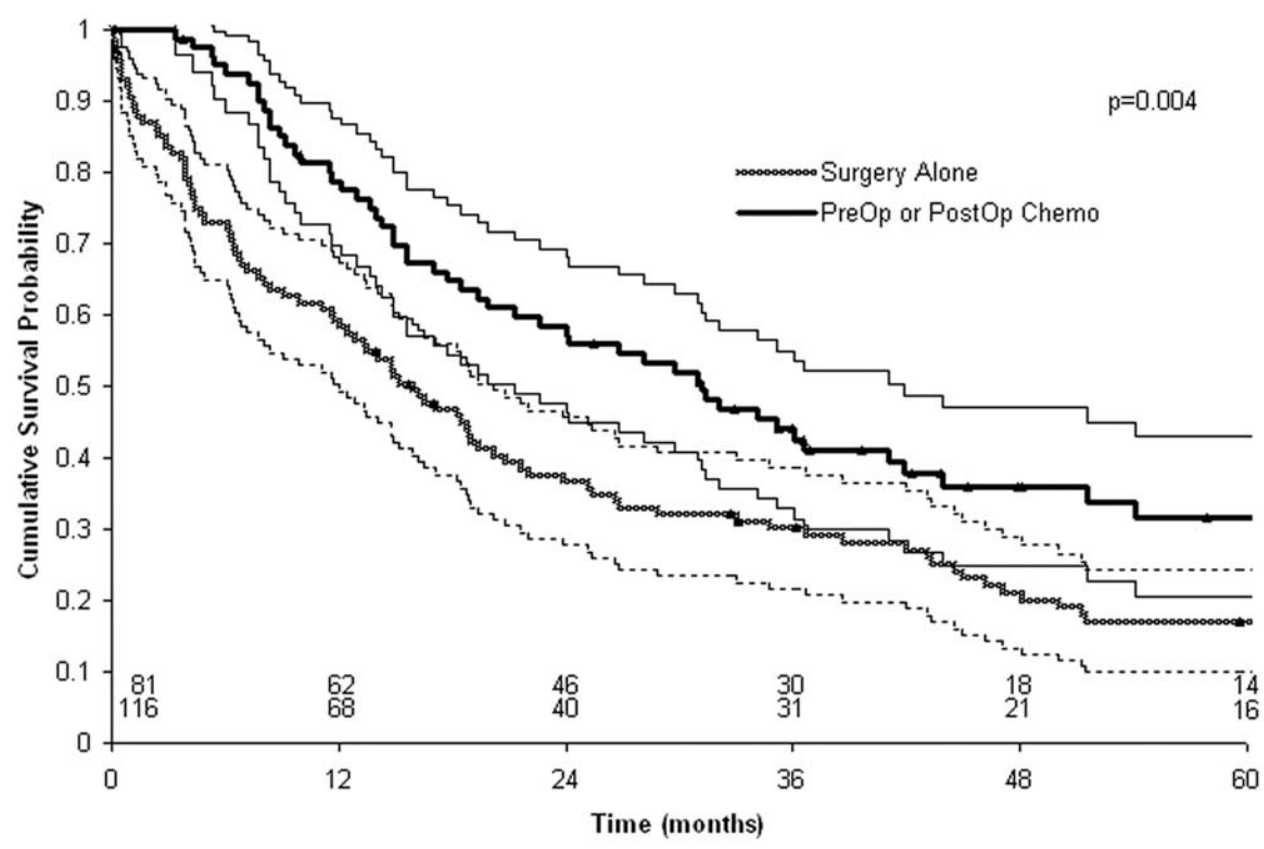

Figure E1. Survival comparing preoperative or postoperative chemotherapy $(n=81)$ versus surgical intervention alone $(n=116)$. Ninety-five percent confidence intervals are displayed. Solid lines, preoperative or postoperative chemotherapy; dashed lines, surgical intervention alone.

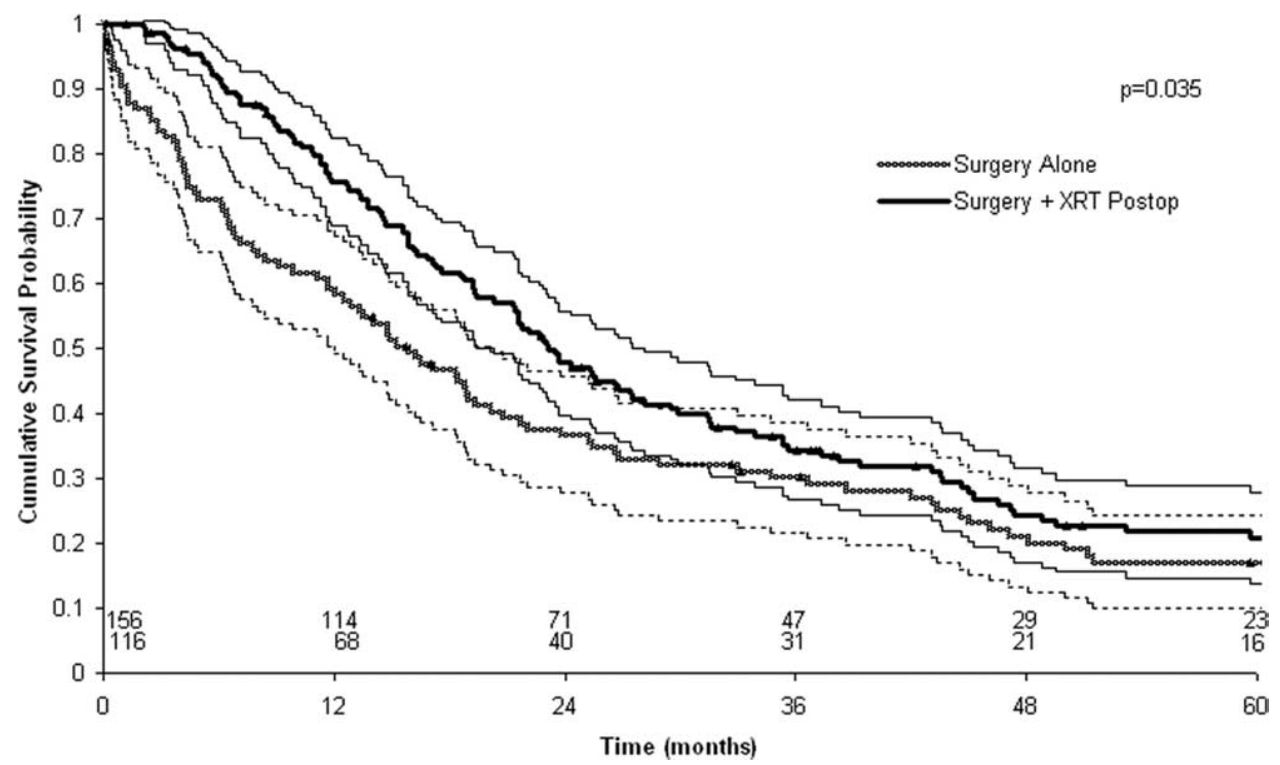

Figure E2. Survival comparing surgical intervention followed by radiation therapy (XRT; $n=156)$ with surgical intervention alone $(n=116)$. Ninety-five percent confidence intervals are displayed. Solid lines, postoperative radiation therapy; dashed lines, surgical intervention alone. 


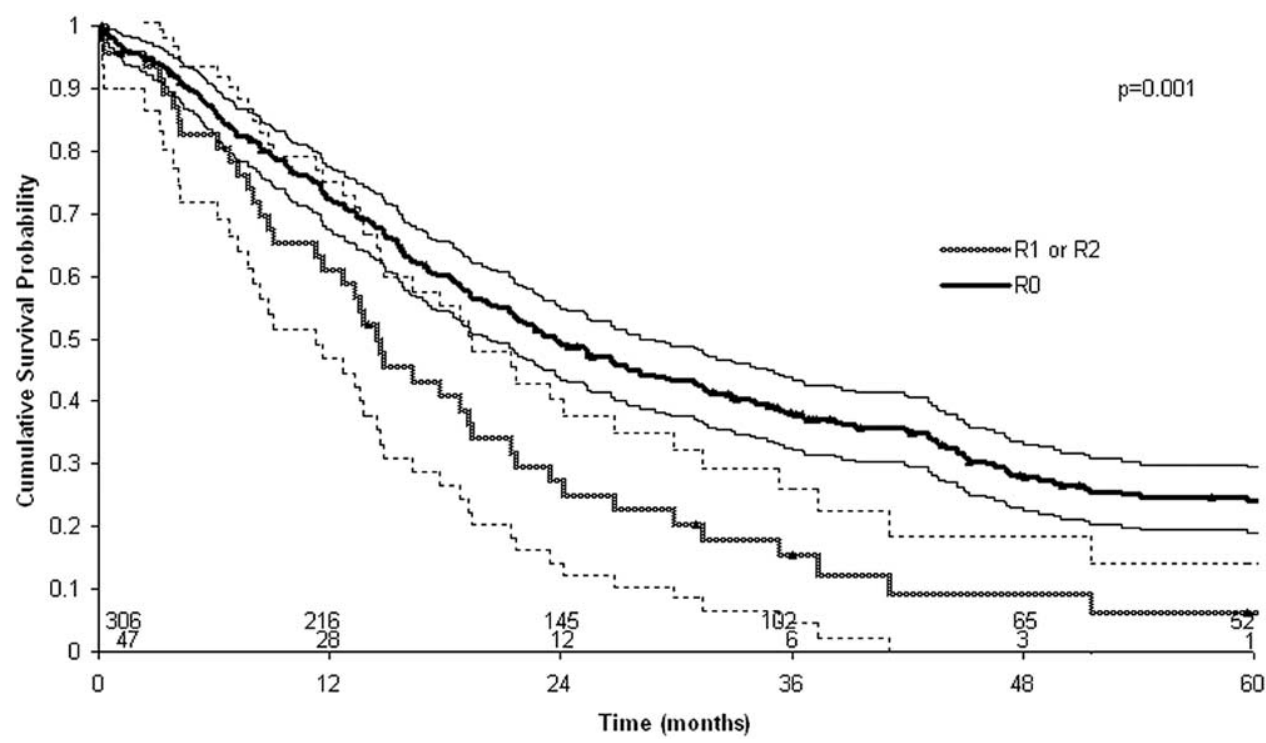

Figure E3. Survival by extent of resection (R0 $[n=306]$ vs $R 1$ or $R 2[n=47]$ ). Ninety-five percent confidence intervals are displayed. Solid lines, RO; dashed lines, R1 or R2. 